\title{
ILCEA
}

Revue de l'Institut des langues et cultures

d'Europe, Amérique, Afrique, Asie et Australie

$26 \mid 2016$

Mémoire, vérité et justice en Uruguay

\section{Trauma social, memoria colectiva y paradojas de las políticas de Olvido en el Uruguay tras el terror de Estado (1973-1985): memoria generacional de la post-dictadura (1985-2015)}

Social Trauma, Collective Memory and Paradoxes of Politics of Oblivion in Uruguay after State Terrorism (1973-1985): Post-Dictatorship Generational Memory (1985-2015)

Traumatisme social, mémoire collective et paradoxes des politiques d'oubli en Uruguay après le terrorisme d'État (1973-1985) : mémoire générationnelle dans la post-dictature (1985-2015)

\section{Gabriela Fried Amilivia}

\section{OpenEdition}

\section{Journals}

Edición electrónica

URL: http://journals.openedition.org/ilcea/3938

DOI: 10.4000/ilcea.3938

ISSN: 2101-0609

Editor

UGA Éditions/Université Grenoble Alpes

Edición impresa

ISBN: 978-2-84310-334-6

ISSN: 1639-6073

\section{Referencia electrónica}

Gabriela Fried Amilivia, «Trauma social, memoria colectiva y paradojas de las políticas de Olvido en el Uruguay tras el terror de Estado (1973-1985): memoria generacional de la post-dictadura

(1985-2015) », ILCEA [En línea], 26 | 2016, Publicado el 07 julio 2016, consultado el 10 diciembre 2020. URL : http://journals.openedition.org/ilcea/3938; DOI : https://doi.org/10.4000/ilcea.3938 


\section{Trauma social, memoria colectiva y paradojas de las políticas de Olvido en el Uruguay tras el terror de Estado (1973-1985): memoria generacional de la post-dictadura (1985-2015)}

Social Trauma, Collective Memory and Paradoxes of Politics of Oblivion in Uruguay after State Terrorism (1973-1985): Post-Dictatorship Generational Memory (1985-2015)

Traumatisme social, mémoire collective et paradoxes des politiques d'oubli en Uruguay après le terrorisme d'État (1973-1985) : mémoire générationnelle dans la post-dictature (1985-2015)

Gabriela Fried Amilivia

La represión se alimenta de silencio Hijos Uruguay. Ir hasta donde están los recuerdos, ver cómo son y ponerlos en palabras. Para así crear el olvido. El olvido no es la falta de memoria: son los recuerdos que se fueron a su sitio, el país del olvido, organizados en palabras. Lo contrario de la palabra no es el silencio: es el vacío. El silencio, lo que no se

dice, es también un modo de recordar. Lo recuerdo, pero no me lo digo. Si no me lo digo, difícil será olvidarlo. 


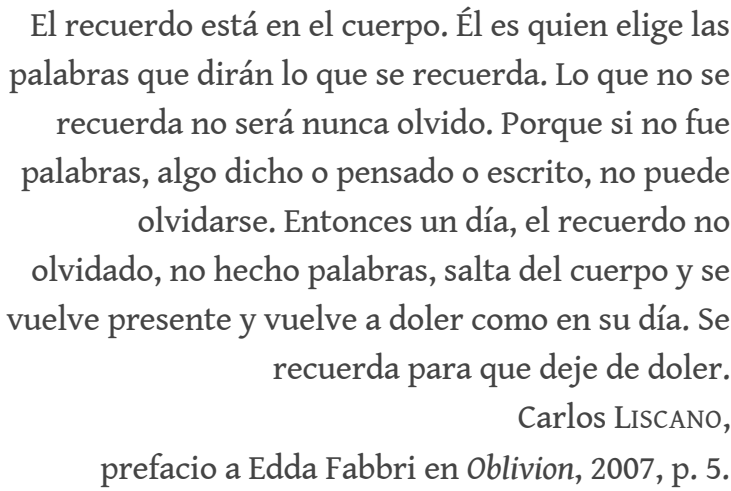

\section{Introducción}

1 Los regímenes políticos represivos del mundo entero han intentado controlar no sólo las instituciones de la memoria y la Historia, sino también sus fuentes: la capacidad de los pueblos de rememorar y transmitir el pasado de violencia. Desde los juicios de Nuremberg tras la Segunda Guerra Mundial, los movimientos sociales por la memoria y justicia frente a las responsabilidades de los Estados a propósito de violaciones de los derechos humanos durante guerras, genocidios, apartheid y regímenes políticos autoritarios y totalitarios han crecido exponencialmente. Desde España a Argentina y Uruguay, Sud-África y Europa del Este, Timor del Este y Perú, las víctimas de estos atropellos por parte del terrorismo y la barbarie practicados desde el Estado son las que se han movilizado para demandar el reconocimiento público y para manifestarse contra la negación y el olvido de su sufrimiento, sufrimiento que se ha presentado con creciente frecuencia en términos de experiencia traumática.

Este trabajo reflexiona acerca de los procesos transicionales en el caso uruguayo, dentro del contexto del post-autoritarismo latinoamericano y sus políticas transicionales. Utilizo el legado de las memorias traumáticas post-autoritarias y las subsiguientes políticas transicionales como el lente con el cual analizar algunos de los complejos procesos culturales de lo que podría ser llamada la dimensión colectiva del trauma a partir de este periodo, en la intersección entre políticas de Estado, violencia política y el uso de la violencia y la negación como políticas de Estado.

En el contexto de la «Doctrina de la Seguridad Nacional» (Landau, 1988; Blixen, 1998; Dinges, 2003) patrocinada por el liderazgo de los EE. UU. durante la Guerra Fría sobre la base de la noción de una guerra interna contra la «subversión» comunista en los años 1960-1980, la desaparición forzada ${ }^{1}$, la prisión prolongada y la tortura, el exilio e incluso el «insilio» (al decir del desplazamiento interno y la clandestinidad en el neologismo de Mario Benedetti) se convirtieron en instrumentos emblemáticos del terror de Estado ${ }^{2}$. En tanto el Estado uruguayo lanzaba su forma particular de guerra contra la «subversión», su aparato militar desataba una violencia política masiva contra sus propios civiles sin paralelo en la historia de la República.

4 A la salida de la dictadura uruguaya, el régimen transicional post-autoritario y la sociedad enfrentaron los legados del terrorismo de Estado implementando una de las políticas de negación y silenciamiento de las violaciones de los derechos humanos durante una de las dictaduras cívico-militar más extremas de la región. Estas políticas en Uruguay fueron llamadas «políticas de Olvido» (1985-2001) en círculos no-gubernamentales y académicos ${ }^{3}$ y fueron popularmente más conocidas como «políticas de impunidad». En nombre de la 
reconciliación y la pacificación, estas políticas negaron el reconocimiento público y la posibilidad de recursos judiciales, legales o morales (redress) a las víctimas de violaciones de derechos humanos, reforzando así el silenciamiento del debate y de la emergencia pública de las memorias de las experiencias de la desaparición forzada, de la cárcel política, de las torturas y del exilio.

El pilar de estas políticas fue la aprobación de una ley el 26 de diciembre de 1986 resultado de un largo proceso de consenso de las élites- oficialmente llamada Ley de Caducidad de la Pretensión Punitiva del Estado 4 . Esta ley absolvía a todos los mandos militares y policiales subalternos de todo crimen cometido durante el régimen militar, sin investigación, reconociminto o proceso previo alguno. Esta ley tenía el objetivo de «dar vuelta a la página» (según la expresión usada en aquel tiempo) y sería altamente debatida y combatida desde la campaña popular pro-referendum que se organizó luego de su aprobación. A pesar de una intensa movilización política (1987-1989) -que dejó sus huellas culturales hasta hoy- las sanciones de esta ley tanto por el Ejecutivo y el Senado como por un margen mayoritario de la población (que sin embargo expresaría una intensa polarización del tema) actuarían como un «doble sello» político (la expresión usada en aquel tiempo) a las violaciones de los derechos humanos durante la dictadura, aún irresueltas hasta el día de hoy (Roniger, 2001: 163; Fried \& Lessa, 2011; Burt, Fried \& Lessa, 2013; Burt, Fried \& Lessa, 2015; Marchesi, 2013, 2014).

6 Por más de una década (1989-2001), la política nacional no se refirió públicamente a los temas «del pasado reciente» (como se alude pública y eufemísticamente a temas del pasado autoritario y las violaciones de los derechos humanos), que permanecieron silenciados. Los medios masivos continuaron ejerciendo auto-censura sobre el tema de la responsabilidad del Estado en dichas violaciones. Asimismo, la historia de la dictadura no fue enseñada regularmente en las escuelas públicas hasta pasados los años 2000. El Estado había decretado que la dictadura «había pasado» y que el pasado estaba «sellado». Una larga década de silenciamiento seguiría a los años de efervescencia de la apertura democr ática.

7 Pero hacia fines de 1990, inesperadamente, el paisaje político de denegación y olvido o «sellamiento» de los crímenes del terrorismo de Estado comenzaría a cambiar y a mostrar señales de desgaste, a medida que la memoria de los abusos del pasado comenzaba a irrumpir nuevamente a la luz pública, emergiendo del silencio y olvido a los que las políticas transicionales iniciales habían intentado condenarla. Podemos encontrar la clave de este «renacer» de la memoria en el incansable trabajo y resurgir de los movimientos sociales por memoria y justicia ante los abusos «del pasado reciente» que reaparecen públicamente en forma creciente y exponencial en particular desde fines de los años 90 (Burt, Fried \& Lessa, 2013, 2015).

8 Las políticas de olvido habían intentado poner un sello al pasado. Sin embargo, en vez de menguar con el paso del tiempo, estos problemas paradójicamente reemergieron en la memoria pública con el paso del tiempo. Los «problemas irresueltos del pasado» afloraron por los resquicios del muro de silenciamiento y olvido en forma de demanda e interés públicos crecientes, hasta ser hoy un tema aún no resuelto pero aún muy presente en la memoria social y cultural. Este efecto paradójico es precisamente lo que buscamos poder explicar.

9 El caso uruguayo es ejemplar. Pone de relieve cómo las memorias de experiencias traumáticas motivadas por conflictos políticos y violencias de Estado pueden ser mucho más resilientes de lo que se había pensado. La resiliencia misma de las demandas públicas 
continuadas a través de ya cuatro décadas, a contra-corriente de los esfuerzos políticos por parte de las élites y sus instituciones políticas y sociales para suprimirlas, están precisamente en el centro de la cuestión a examinar tanto en la teoría como en las prácticas sociales: ¿cómo es que estas memorias colectivas del terrorismo de Estado han persistido socialmente para ser transmitidas no solamente en el espacio privado e íntimo de las víctimas y sus familias, sino también en el espacio público y cultural social aún dentro de un contexto de olvido, silenciamiento e impunidad institucionalizados? Aquí subrayo los conflictos subyacentes a nivel intersubjetivo de las memorias de un pasado que aún décadas después no ha sido reconocido ni procesado cabalmente. Por lo tanto, es una memoria de un pasado «no-pasado» que permanece presente en el entramado de la cultura, de la política, de relaciones intersubjetivas sociales y en las sensibilidades contemporáneas de la nación.

El argumento central aquí es el siguiente: aquello que la memoria política pública oficial, por así decirlo, excluyera por décadas, fue paradójicamente sostenido y revitalizado en principio dentro de las esferas culturales e íntimas de las transmisiones privadas de memorias en el seno de las familias y comunidades de memoria - lo que llamamos el nivel intersubjetivo formativo de la memoria. Tal sustento al amparo de procesos culturales íntimos y privados hizo posible que las memorias colectivas pudieran ser re-construidas y se mantuvieran relativamente accesibles para su uso por la cultura popular una vez roto el período de silencio. Quiero aquí conceptualizar lo que llamo el nivel formativo de la memoria, el nivel de las corrientes sumergidas de memorias privadas (les sous-courants de mémoire, en el trabajo original de Maurice Halbwachs La Mémoire collective, póstumamente publicado en 1950) a través de las generaciones familiares, políticas y socio-culturales. $\mathrm{Si}$ bien mi trabajo en la última década ha incluído los casos de desapareción, cárcel política y exilio, amén de otros grupos afectados por la represión política, en este ensayo me centro en el problema de la memoria del trauma social aplicado al caso uruguayo en su sentido general.

\section{El problema y su contexto: el terror de Estado y las políticas transicional del Olvido (Oblivion)}

11 Las crecientes olas públicas de memoria de fines de los 90, tras un período de largo silencio que en su momento parecía impenetrable, pusieron en evidencia los conflictos subyacentes del pasado en el entretejido de las políticas contemporáneas. Estas olas fueron efectos de las experiencias no-procesadas, experiencias para las que no hubo reconocimiento ni duelo, experiencias suspendidas en un limbo, que no hallaban espacio social o psíquico. El espacio social, debido a las movilizaciones y rituales privados y colectivos hacia políticas de memoria, justicia, y de reconocimiento de los derechos de las víctimas -y los cuidadanos todos- a la memoria, la historia y el Nunca más, poco a poco fueron caldeándose y abriéndose el paso en las corrientes subterráneas de las memorias colectivas más íntimas. A pesar del silencio y del no reconocimiento públicos, habían permenecido, ocupando espacios subjetivos e intersubjetivos, sobreviviendo $\mathrm{y}$ sosteniéndose en el secreto e intimidad de las vidas privadas, personales y familiares, y en los vericuetos íntimos de individuos, sus familias y comunidades, e incluso a través de las generaciones que vivieron el período de la represión de Estado, en sus diferentes niveles de afectación. 
12 Lo que había sido en un primer momento excluido en la memoria política y cultural pública oficial, paradójicamente había retenido una profunda presencia social y cultural, primeramente en comunidades de personas que se sentían directamente afectadas (vale indicar que no todos los directamente afectados objetivamente se reconocen o identifican como «afectados» en su subjetividad). Finalmente, estas memorias no reconocidas comenzaron a emerger desde el ámbito íntimo privado y subyacente hacia la esfera política pública a fines de los 90 . Pasados casi 15 años del inicio de la transición, llegaron a emerger en la escena política mediante procesos populares, «desde abajo», de movilizacion social de liderazgo, interrogando y forzando a las élites a responder y actuar (bottom-up). Este proceso se desarrolla en un proceso sostenido por lo que considero aquí como la capa formativa (o nivel formativo) de las corrientes subyacentes de la memoria de la represión política, de acumulaciones de significaciones y transmisiones éticas y morales, en el nivel de las transmisiones privadas de memoria de las víctimas o personas que se reconocen e identifican como directamente afectadas dentro de sus familias y comunidades: las transmisiones de memorias y sentidos entre los familiares y comunidades de personas desaparecidas, de personas presas políticas y de personas exiliadas a través de las generaciones.

(1985-2000) habían contado con el poder del tiempo pensando que estaba de su lado, o sea que se pensaba que con el paso del tiempo y a medida que irían falleciendo los últimos sobrevivientes y testigos, los últimos vestigios del pasado problemático se borrarían. Sin embargo, de hecho, las políticas de negación y silenciamiento no lograron ni el cierre del tema, ni la reconciliación social que se esperaba. Bajo un fino barniz de consenso, las polarizaciones persistieron durante décadas. Con el paso del tiempo surge una paradoja inesperada: el pasado no solamente no era pasado, sino que estaba o se presentaba, valga la redundancia, como cada vez más presente. Periódicamente, ciclos de debates públicos y movimientos contestatarios de memoria emergieron (en 1995-1996, en 1999, y con mayor fuerza nuevamente en 2000 y decididamente durante la última década, desde 2005$)^{5}$ para romper el silencio sobre las responsabilidades y participación del Estado y abrir el debate cívico nacional ante los abusos de los derechos humanos - sin precedentes en la región desde el advenimiento de la independencia nacional y la democracia- cometidos bajo la dictadura y continuando en la post dictadura.

La pregunta que demanda respuesta es: ¿cómo es que este «sello» político y cultural de las memorias de la represión política en el Uruguay se va gradualmente «des-sellando» hasta llegar a abrirse públicamente (en particular a partir del año 2000)? ¿Cómo es que estas experiencias dolorosas persistieron en las memorias colectivas, incluso en generaciones a través del tiempo, para romper pactos de silencio? represión, reside en la naturaleza social traumática de estos procesos por los cuales estas experiencias fueron empujadas desde lo político público al campo de lo cultural, y desde las esferas públicas hacia las privadas.

El doble sello político y social sobre el pasado de abusos de la represión política, que vinieron a fortalecer las políticas de Estado de negación, silenciamiento y olvido, había forzado a aquellos que fueron directamente afectados a recurrir a sus propios recursos privados y comunidades civiles. El espacio social que estas víctimas tuvieron para resistir y sostener una ética de la memoria, verdad y justicia se alejó del terreno político hacia el terreno cultural, y de la arena pública hacia la arena privada. Mi estrategia metodológica 
se centra entonces en las corrientes subyacentes íntimas de transmisión de memoria entre las generaciones de familias que vivieron y sufrieron la represión de la dictadura y sus descendientes (Fried, 2006, 2009, 2016) en las primeras dos décadas de transición.

En las próximas secciones desarrollo el concepto de trauma social en la literatura anglosajona reciente fundamentalmente en ciencias sociales (sociología) y presento un caso testimonial en el momento clave en que la memoria privada comienza a circular públicamente, a través de la carta de una madre, ex presa política y esposa de una persona detenida-desaparecida, a sus hijos, que circula a través del proyecto colectivo Memoria para Armar (2000-2002). En las conclusiones cierro con un breve análisis politicocultural del caso de transición uruguayo, y con la presente administración Vázquez y el trabajo en curso del Grupo de Trabajo Verdad y Justicia.

\section{La transmisión de las memorias del terrorismo de Estado (y la desaparición forzada) en el Uruguay}

Para entender este efecto paradójico de la memoria a través de las generaciones en sus memorias íntimas, culturales, y políticas, es necesario demarcar conceptualmente algunas nociones como la intersubjetividad de la memoria traumática a nivel cultural y colectivo. Para ello me baso aquí en desarrollos de la literatura contemporánea en ciencias sociales, desde la ya clásica definición de trauma colectivo de Kai Erikson (1976) como «un golpe a la solidaridad de la comunidad que se manifiesta de forma retroactiva a través del tiempo» ${ }^{6}$, y construyo sobre los trabajos de Jeff Prager ${ }^{7}$ sobre la intersubjetividad de la memoria $(2004,2004 \mathrm{~b})$ y sobre la relación entre trauma, duelo y temporalidad (Prager, 2003, 1999; ver también Volkan, 2002 y Alexander \& Smelser, 2004). Estos trabajos más recientes desde la sociología cultural, la psicología social y las humanidades se han venido distanciando de nociones médicas y literales del trauma (como golpe físico) que emergieron de las guerras mundiales ${ }^{8}$. Estos avances ofrecen una noción de trauma situado no en los eventos mismos sino en el sentido que los sujetos dan a la experiencia de los mismos como resultado de procesos personales y colectivos subjetivos y de reconstrucción retrospectiva (Caruth, 1995; Prager, 1999, 2003, 2004). El daño del trauma, pues, se puede entender por «las formas en que es internamente procesado y registrado» (Prager, 2004: 2). En ese sentido, el trauma trabaja en el sentido de un proceso de distorsión de la memoria (ibíd.), proceso que altera las capacidades reflexivas y reconstructivas de la memoria y que dan significación a las experiencias.

En contraste con la definición médica «literal» del trauma como «herida» psíquica como resultado de un golpe súbito único o de shock, en el cual el trauma es visto como emanando de los eventos o experiencias mismos sin reconocer el hecho de que ha habido un lapso de tiempo entre los eventos en sí mismos y su retorno en la memoria (Prager, 2003: 3), los analistas sociales y culturales están comenzando a concebir a la memoria traumática como un proceso que es indudablemente mediado culturalmente y contextuado socialmente (socially embedded process) (Alexander \& Smelser, 2004; Prager, $1999,2003,2004)$. No es solamente la naturaleza de los eventos lo que es traumático, sino también deviene traumática la forma en que los sujetos y colectividades experiencian y dan interpretación y sentido a esos eventos. En este sentido, la experiencia traumática es el resultado de un proceso de interpretación donde el sujeto / los sujetos ponen los eventos en su contexto (Alexander \& Smelser, 2004). El desarrollo y manifestación del trauma 
solamente puede suceder de forma retrospectiva a medida que los sujetos recuerdan y reconstruyen la experiencia vivida de forma significativa después de que los eventos ya han concluído (Prager, 2003: 3).

Es importante remarcar que el trauma se experiencia a través de un proceso de construcción de sentido e interpretación que implica la internalización y desarrollo de procesos de identificación intersubjetivos. Tanto la experiencia pasada traumática y la vida presente de los sujetos se ve mediada por procesos (inter)subjetivos y culturales significativos (de construcción de significados) así como por procesos propios del mismo paso del tiempo (incluyendo los tiempos sociales). Estos procesos dan forma a cómo los sujetos pueden entender y dar significados distintos a sus experiencias (Prager, 2003: 3). Esto sugiere que necesitamos examinar «las formas en que la experiencia ha sido memorializada por aquellos que la sufren, no solamente por el reconocimiento de la realidad» (Prager, 2003: 6) 9 .

Dentro de estas conceptualizciones, el trauma ofrece las siguientes características:

\section{a) El trauma social como pasado no metabolizado}

Como afirmamos más arriba, lo traumático no radica en la naturaleza de los eventos mismos, sino en la forma en que los sujetos y colectividades experiencian esos eventos y les dan significado en contextos socio-historicos específicos. Mi trabajo subraya la naturaleza procesual, cultural y de construcción de sentido y el carácter intersubjetivo y encarnado ( embodied) de una noción sociológica de trauma social como efecto de violencias políticas.

El trauma afecta cómo los sujetos experiencian la noción subjetiva del tiempo. Halbwachs (1992/1950), el ilustre sociólogo francés, discípulo de Durhkheim, pionero en estudios de memoria social de la primera mitad del siglo xx, ya había reconocido la notable capacidad del trauma para distorsionar la experiencia subjetiva del tiempo y el procesamiento de la memoria misma (Fried \& Takita-Ishii, 2014). La memoria traumática no solamente se procesa a través del tiempo y a través de las generaciones (Friedlander, 1979; Danieli, 1998; Herzog, 1982), sino que distorsiona el sentido mismo -a nivel personal e históricodel tiempo de los sujetos que la experiencian. Ello sucede cuando «eventos o experiencias anteriores interfieren o invaden al ser en el presente (present day being-ness) (Prager, 2003: 1), a medida que imágenes mentales del pasado irrumpen en el presente (Volkan, 2002: 45,157 ), produciendo una sensación de «temporalidad» (Leys, 2000) o de «tiempo colapsado» (Volkan, 2002: 157); o, como he observado en los propios sujetos de mis estudios en el caso uruguayo hasta los años 2000, de «tiempo congelado».

Como resultado de estas distorsiones del tiempo y de la memoria, encontramos que el trauma de alguna manera "posee» a sus víctimas (Caruth, 1995: 152-53), transformando su mundo a su imagen (Prager, 2003: 4). Esto afecta la capacidad de los sujetos de mantener una sana distancia entre la experiencia del pasado y cómo entienden, procesan y dan sentido a los eventos en el presente y a través del tiempo (Caruth, 1995: 152-53, en Prager, 2003: 2).

De acuerdo con esta perspectiva (que podría calificarse de intersubjetiva o psicoanalíticacultural), entiendo al trauma como resultado de un proceso en que las memorias nometabolizadas de un pasado social vienen a ser re-experienciadas de forma repetitiva «como si el pasado fuera presente». De esta forma, el pasado se vuelve parte nuestra como dijera brillantemente el sociólogo norteamericano Michael Schudson, otro estudioso de la 
memoria y la cultura. Desde esta perspectiva, el pasado no solamente es maleable constantemente desde el presente (como se dijera en una de las lecturas más populares de Halbwachs) sino que el peso del pasado (como famosamente dijera Marx) viene a ocupar espacio en el presente. Este proceso no necesariamente se desarrolla en favor de tradiciones sino también es posible entenderlo, en particular desde la modernidad, en el sentido de proceso de cambio traumático que deja sus síntomas histórico-sociales en el cuerpo social.

\section{b) El trauma como pérdida o duelo no elaborado (Un-mourned Loss)}

La noción de trauma en este sentido intersubjetivo implica una teoría de la experiencia subjetiva de la pérdida - de cómo la experiencia extrema (de vulnerabilidad, de dolor, de pérdida) se puede volver una experiencia a ser procesada internamente. En este sentido, el marco socio-psicoanalítico de Jeff Prager enfatiza que «la identidad es inter-psíquica, resultado de la confrontación de un individuo estructurado dinámicamente con un mundo social lleno de expectativas y formulaciones pre-figuradas acerca del self. El proceso de duelo requiere tanto un ser doliente que hace el duelo que pueda tolerar el dolor así como un mundo externo [social] que pueda ayudar y apoyar [al individuo] en ese proceso» (Prager, 2004: 6) ${ }^{10}$. Este proceso de duelo inserto en el proceso social ilustra bien cómo nuestra experiencia humana de la realidad externa es inevitablemente mediada psíquicamente y cómo ello nos da un marco más sutil, un espectro de colores más amplio para pensar la relación entre lo subjetivo y lo social, un mapa o radar para poder pensar cómo «la realidad psíquica hace su propia contribución distintiva a la vida social, [realidad psíquica] que transforma activamente al mundo social en tanto es asimismo transformada por él» (Prager, 2004: 7). El trauma así entendido, entonces, es el resultado de la falla del ámbito social en proveer protección contra «elementos constantemente intrusivos que le recuerdan al sujeto que el mundo ya ha demostrado no ser seguro, ni reasegurador, ni entero. Cuando estas condiciones [sociales] prevalecen, la memoria interfiere y el pasado traumático domina [a los sujetos]» (Prager, 2004: 3). De acuerdo a esta perspectiva, el trauma persiste entonces no debido a una patología individual, del individuo en sí, sino como resultado de un proceso social fallido, «incapacitado para permitir su conclusión o cierre» (Prager, 2004: 3). A partir del terrorismo de Estado, puede decirse que el proceso dictatorial y transicional uruguayo ha sido traumático no solamente porque fuera perpetrado activamente como parte de un plan sistemático por agentes militares del Estado en colaboración con agentes civiles, sino también sostenido por condiciones e instituciones socio-politicas y culturales que los hicieran posible: las llamadas políticas del terror y silenciamiento y posteriormente el olvido y la negación prolongada del terror. En ese sentido, el trauma no es aquí un proceso psíquico patológico que se desarrolla a nivel individual, como una distorsión en la memoria de un sujeto individual, aunque pueda presentarse así - sino como un procesamiento sociocultural de eventos que aún no han sido significados por la sociedad en su conjunto, ni procesados en su sentido histórico. Son procesos que corresponden a cambios profundos en la identidad y autopercepción nacionales a través de las décadas, épocas y generaciones. No estamos hablando aquí de una relación diádica entre perpetrador y víctima, sino de procesos sociales masivos a través de procesos históricos y culturales. 


\section{c) Deberes morales acarreados por las memorias traumáticas}

27 Las memorias traumáticas, hemos dicho, distorsionan el presente y destruyen (o transforman radicalmente) el futuro proyectado. Según la imagen de Ricœur, «llevan un peso del pasado para ser enfrentado en el futuro» (1999: 94). El trauma así visto es como un fantasma que viene de la muerte a «habitar el presente» y toma como rehén a los vivos sin dejarles tomar distancia alguna (Ricœur, 1999: 41). Es un pasado que no retrocede y que conlleva ciertos deberes u obligaciones que «paralizan a la memoria, y por extensión, a su capacidad de proyectarse creativamente hacia el futuro» (Ricœur, 1999: 62). Muchos sujetos entrevistados directamente afectados por el trauma han descrito este peso o ancla como un sentido del deber que ha cambiado sus vidas y formas de ser, de experienciar y percibir la realidad. Por ejemplo, una madre cuyo hijo desapareció en Uruguay me dijo: «lo considero un deber, es por eso que seguimos... [...] Pienso en mi hijo desaparecido, y pienso: ¿cómo no seguir haciendo algo por él?» Otra madre me dijo: «lo que pasó [en Uruguay] no puede pasar nunca más... [...] Así es como esto se vuelve parte de vos, se transforma en parte de tu carne» ${ }^{11}$.

Muchos uruguayos cuyas familias y comunidades sufrieron la desaparición, la cárcel política, el exilio, u otras calamidades y efectos del terrorismo de Estado durante la pasada dictadura cívico-militar me han sugerido que cuando la sociedad olvida y no ofrece soluciones a las víctimas, entonces ellos - la sociedad toda- «condena» a las víctimas a la memoria.

La obligación moral de los sobrevivientes a recordar se tornó más fuerte aún cuando el Estado uruguayo intentó no sólo el olvido sino la supresión de las huellas de la violencia ejercida como política de Estado, para evitar mediante un elaborado sistema de impunidd el reconocimiento y las consecuencias de sus responsabilidades (accountability). Los sobrevivientes por todo el mundo, bajo similares condiciones de daño moral, psíquico y físico, parecen adquirir una poderosa deuda que los obliga a «contar los muertos denegados» (Schmucler en Piralián, 2000: 17). Esta deuda u obligación moral transforma a la memoria aún más profundamente en una forma de contabilidad moral (a moral accounting), en una forma de dar(se) cuenta. Trabajando a partir del estudio antropológico ya clásico (pero frecuentemente ignorado) de Marcel Mauss (1964) acerca de la mutualidad de las «obligaciones morales» y su propuesta de pensar al nivel moral como un sistema de «póliza de seguro social» (social insurance), propongo aquí pensar a la memoria traumática como una fuerza orientada hacia el futuro que significa la emergencia de una «economía moral» (o tal vez también una geografía moral) que se encarga de recordarles a los miembros de la sociedad toda sobre sus quiebres sociales, sus desfasajes, sus deudas pendientes - pagaderas a futuro. En trabajos más extensos he desarrollado esta noción del efecto paradójico de la memoria traumática y su capacidad para destruir y a la vez re-delinear los límites de esas categorías morales sociales al mismo tiempo que logra reforzar las obligaciones mutuas entre los miembros (ver Fried, 2004, 2009, 2016). 


\section{d) La transmisión inter-generacional de la experiencia traumática en la memoria}

30 Mi trabajo ha documentado y corroborado la evidencia de investigaciones sobre el trauma desde la psicología clínica y el psicoanálisis que muestran que a partir de la manifestación del trauma parental, la segunda generación -e incluso una tercera- puede llegar a experimentar memorias traumáticas «vicarias» (Bergman \& Vuckovy, 1998; Volkan, 2002; Fried Amilivia, 2004, 2009, 2011, 2013, 2015, 2016; Lira \& Castillo, 1991; Lira, Salimovich \& Weinsten, 1992; Levey, 2014). Mi trabajo sugiere que los efectos iatrogenizantes traumáticos sobre las generaciones se ven especialmente agravados bajo condiciones sociales de silencio público y denegación continuados, tales como las detalladas bajo las políticas transicionales del olvido y silenciamiento uruguayo, en donde aquellos previamente afectados tuvieron que sobrellevar el adicional peso de las condiciones sociales altamente desfavorables para el reconocimiento y reparación de sus experiencias durante ya más de tres décadas desde el inicio de la transición. Ello da como resultado un proceso social de re-traumatización continuado o prolongado en el tiempo transicional, extendiéndose más allá de los hechos mismos y más allá de las experiencias de una generación de individuos o comunidades específicas que sufrieron la represión directamente, amplificándose y diseminándose en los ámbitos políticos, culturales, intersubjetivos e institucionales de toda la sociedad.

31 La persistencia y transmisión a través de las generaciones de un sentido de «cuentas pendientes» aún no saldadas emergió como un elemento crucial en el problema prolongado de los efectos del período del terrorismo de Estado en el caso uruguayo.

Existe fuerte evidencia (Fried Amilivia, 2004, 2009, 2011, 2013, 2015, 2016) de que esta sensación de un saldo u obligación pendiente, un legado de «problema sin terminar» o «negocio sin saldar» ha pesado con fuerza en por lo menos ya tres generaciones (padres y pares, hijos y nietos de las personas que vivieron en esa época), envuelta en múltiples capas sutiles de secreto y pactos de silencio que extienden sus ramas aún hasta el día de hoy.

33 Un trabajo de investigación empírica e histórico-comparativa a desarrollar tendrá que considerar las siguientes preguntas: si el legado de la desaparición es una memoria que transmite una deuda sin saldar, ¿cómo ha de ser saldada? ¿Acaso las generaciones venideras están inevitablemente «condenadas a la memoria»? ¿Cuánto de este peso cargará la segunda, tercera, incluso cuarta generación? ¿Cuáles son las consecuencias de estas políticas de olvido, silencio e impunidad en el futuro? ¿Bajo qué condiciones sociales alternativas, qué políticas públicas innovadoras, qué prácticas institucionales, sociales, políticas y culturales, podría llegarse a hacer una elaboración y simbolización (si esto último es posible) del legado del terrorismo de Estado, la condición social de la desaparición forzada, la tortura y el exilio e «insilio» de cientos y miles de uruguayas y uruguayos, hoy personas ciudadanas de un régimen de derecho?

La evidencia de las generaciones familiares que he documentado en mi trabajo ha demostrado que los miembros de la segunda generación, lejos de haber olvidado o «curado» sus heridas (si es que ello fuera el debatible objetivo), también están en una lucha o debate interno y han desarrollado sus propias aspiraciones con respecto a las cargas de este pasado que no termina de pasar. La evidencia en el panorama nacional cultural y político públicos, las olas continuadas de la memoria y el aumento de 
movilizaciones sociales que demandan justicia y responsabilidad del Estado también sugiere con fuerza que lejos de haber llegado a una conclusión o cierre, las políticas del oblivion solamente lograron extender y prolongar el problema, dilatando las tareas de la transición política hacia una democracia constitucional plena y un Estado de derecho regido por el principio de igualdad y la separación de poderes. La desaparición forzada, la tortura, los apremios físicos y sexuales a hombres, mujeres y niños uruguayos no pueden olvidarse o cerrarse históricamente por mandato político porque no son temas cerrados: son parte de un pasado que aún sigue presente, que se ha vuelto parte de nosotros. En el Uruguay podría argumentarse que aún no se ha constituido en problema social (planteado públicamente y debatido plenamente). No ha podido ser olvidado, porque es un daño contra la humanidad (Piralián, 2000) y un daño contra la textura central de la identidad nacional y la ciudadanía democrática. No solamente afecta a los involucrados directos (se vean como víctimas o afectados, o no), ataca la trama de la solidaridad social por generaciones, sus valores, normas y sentido de la realidad compartida, expectativas y sueños. Al igual que expone el argumento clásico de Renan, es cierto que una nación se construye tanto por lo que olvida, como por su historia y memoria compartidas. Aunque en algunos casos extremos lo que elige olvidar, más que ampliar el consenso, lo cual tal vez hubiera sido posible antes de la globalización masiva de los medios de comunicación, puede haber ampliado la polarización y la marginación de grupos minoritarios.

Queda claro, escuchando y trabajando con estas historias, que lo que sucedió en Uruguay en el pasado reciente no solamente no es tema cerrado, sino que es como si aún no hubiese «sucedido», en el sentido que aún debe ser construído, reconocido, narrado y elaborado - de una manera análoga a como se procesa un duelo o pérdida, procesado y puesto a descansar en el olvido, ya procesada la memoria dolorosa. ¿Sobre qué condiciones sociales y políticas pueden las palabras que narran estas historias de abuso estatal contra sus propios ciudadanos ser escuchadas y expresadas en público? ¿Y bajo qué proceso democrático serán procesados jurídicamente y responsabilizados en público los crímenes contra los sectores sociales representados por estas comunidades y contra el Estado de derecho y la humanidad toda?

37 Sabemos hoy que el problema del legado del terrorismo de Estado, de la desaparición forzada, de la tortura, del exilio y del insilio, no desaparecerá cuando ya no estén los testigos presenciales. Tampoco es un problema que irá disminuyendo con el paso del tiempo. El trauma social no es un problema que pueda resarcirse o solucionarse desde el dominio privado de familares y comunidades que sufrieran la pérdida de un ser querido, de propiedades, de lugares sociales -aunque ellos han sido pieza clave del sustento de la demanda de verdad, justicia y memoria en los últimos 40 años.

Las historias orales y experiencias subjetivas de familiares, comunidades y personas individuales como resultado del período del terrorismo de Estado (documentados en mis trabajos, por ejemplo, ver 2016, y los trabajos de Gatti, 2014) han demostrado a lo largo de estas últimas décadas de emergencia de expresiones de este legado que, bajo condiciones socio-políticas y culturales de extrema negación y silenciamiento, la habilidad de comunidades e individuos para procesar el trauma fue severamente afectada. Para el año 2000, los regímenes del terrorismo de Estado habían sido completamente eliminados en la región. Pero el legado de esta era de violencia política se continuó perpetrando a través de los regímenes y la cultura de impunidad. Ello fue visible en muchos aspectos, incluída la increíble banalización de los crímenes para el observador externo, las marcas 
en el lenguaje elíptico y eufemístico para referirse a la época, en la dificultad para procesar las pérdidas sufridas y los duelos, en el sentido intuitivo de la existencia de «cuentas pendientes» -y en los efectos culturales y psico-sociales emocionales en las personas y sus colectivos- que aún están siendo procesados hasta el día de hoy.

Ambos niveles de la violencia (cultural y emocional, a nivel individual y colectivo) requieren un análisis más sutil y sofisticado de los diferentes niveles de afectación de lo que suelen recibir en la literatura corriente de los procesos transicionales (con importantes excepciones, entre otros Fried \& Lessa, 2011; Burt, Fried \& Lessa, 2013; Skaar et al., 2015). A pesar de las condiciones extremas ya detalladas (o quizás debido a ellas) fundamentalmente un contexto cultural intolerante de expresión alguna de duelo, pérdida, y de expresiones emocionales de sufrimiento y procesamiento psicológico- $\mathrm{y}$ de su circunscripción a comunidades privadas hasta bastante recientemente, hay evidencia creciente de la persistencia de las memorias y transmisiones de la era del terrorismo de Estado -inclusive entre las generaciones jóvenes que en 2009 votaron masivamente contra la Ley de Caducidad- que las olas de memoria tanto a nivel de las memorias colectivas como de la memoria cultural han persistido a través de las generaciones y van en aumento en nuevas comunidades de memoria que emergen prácticamente cada día. La reparación social sólo puede avanzar cuando todos los niveles de afectación del proceso del terror de Estado, incluidos los agentes que contribuyeran a perpetrarlo (por efecto activo, por defecto o negligencia), y la comunidad social, lo reconocen como propio. El daño social fue ejercido por una pluralidad de esferas sociales e instituciones y se extendió a un daño moral que alcanzó a la comunidad nacional toda.

Lo que sucedió en el Uruguay de los años 1960 hasta mediados de los 1980, el llamado "pasado reciente», ni siquiera es pasado. Aún no ha sido reconocido, procesado, escuchado y compartido en un discurso cívico nacional que integre a la comunidad toda -con sus instituciones políticas, sociales, judiciales, educacionales e interpersonales. Más arriba, al desarrollar el concepto de trauma social hablaba de que el trauma, más allá de sus dinámicas psicológicas, puede ser sustentado, temperado, agravado o amplificado por condiciones «ambientales» sociales, políticas y culturales. Los efectos y metamorfosis del trauma en la identidad histórica uruguaya han sido profundos y se extienden hacia proyecciones futuras. Formas de duelo suspendido y el olvido en el nivel íntimo privado y en los niveles colectivos y culturales intersubjetivos tienen puntos de intersección y de inflexión. El momento presente, a más de 40 años de los hechos -y luego de las décadas de impunidad que los siguieran- es probablemente uno de esos momentos.

\section{La carta de Lango: de madre a hijo}

41 Esta carta que sigue, emergiendo desde lo privado y devenida en acto público a través del colectivo Memoria para Armar, ilustra elocuentemente la sensación de «deuda pendiente» de la generación de la dictadura a sus hijos, debido al sentimiento de culpa ante lo que sienten que les forzaron a vivir y debido al legado del silencio, aun décadas después de la experiencia. Esta madre, Gianella (seudónimo firma Lango), una joven de Montevideo que había sido detenida en 1975, escribe esta carta en 1999-2000, casi 25 años después de los hechos, cuando sus hijos ya son universitarios. Por primera vez incluye detalles íntimos de su tortura (que aquí omitimos) y alude explícitamente al silencio de décadas que coadyuvara al daño de la tortura a perpetuarse (en este tema se centra la selección siguiente): 
Este relato me lo debo y se los debo a Ustedes tres, queridos hijos. Se los debo también a las queridas compañeras con quienes hemos emprendido esta difícil tarea de reconstruir la memoria colectiva. No resulta fácil aún hoy, con la distancia del tiempo transcurrido, ya que recordar implica volver a sentir, a vivenciar, los fuertes sentimientos, dolores y emociones por los que pasamos en aquella época. No resulta fácil tampoco darle un significado a todo lo que sucedió. Pero estas dos cosas son justamente las que nos importa transmitirles. Por lo tanto, creo que vale la pena intentarlo, así como valió la pena vivir todo lo que vivimos en esos años, porque si bien han sido grandes los sufrimientos y las pérdidas, grandes han sido también los aprendizajes. Todos estos días, desde que empezamos a leer los testimonios, me acuesto y me levanto «escribiéndoles» a ustedes... Es curioso como todos estos años me ha acompañado la convicción de no haberles ocultado nada y, simultáneamente, la sensación de zonas oscuras, relatos incompletos, implícitos, sobreentendidos. Mi constante preocupación en el exilio y luego aquí, en el desexilio, era hacerles saber no sólo el porqué y el para qué de la cárcel, el exilio, las pérdidas, sino también el amor, la solidaridad, la bronca, la impotencia: quiénes éramos y cómo llegamos hasta el presente. ¿Cuántas veces me he preguntado cómo y cuándo hablarles de esto? ¡Y sin embargo, qué difícil encontrar el momento y la forma de transmitirlo! Las palabra salen torpes y cuando salen lo que me falla es la memoria, ésa que queremos armar entre todas está en mí llena de olvidos, de lagunas, puntos oscuros.

Y a pesar de eso hoy quiero contrales: porque el relato tiene el poder de no sólo sanar heridas, sino que a través de él les puedo ofrecer un pedacito de historia que es de ustedes también, que les corresponde. [...] En 1975, las Fuerzas Conjuntas ya habían perfeccionado sus «métodos»: el que caía preso era sometido a torturas sistemáticamente en manos de esos personajes siniestros y cobardes que vestían el unifome del Ejército de nuestro país.

Yo no fui una exepción.

Los días de interrogatorio y tortura fueron muy duros, tanto que mi mente ha borrado gran parte de esos días (¿meses?). Sin embargo las huellas que tuve en el cuerpo tardaron bastante en borrarse (¿se borraron?). [...]

Durante mucho tiempo oculté esa parte, como si así me doliera menos, o me preservara del daño. ¡Qué paradoja! Así como las niñas abusadas sexualmente sienten la vergüenza que deberían sentir el abusador por el acto perpetrado, yo sentía vergüenza por lo que me habían hecho... y no lo contaba, sin darme cuenta que de esa manera los estaba protegiendo a ellos. [...]

Mi silencio, el haberme quedado con esto, adentro durante tanto tiempo fue quizás su única victoria sobre mí, y eso me ha hecho mucho daño. El silencio no ha sido bueno para mí. El silencio no es bueno para nosotras ni para ustedes, queridos hijos. Tenemos que contar lo que nos pasó a todos; por nosotras, por ustedes, por los que vendrán: para que cosas así no vuelvan a pasar, para que ustedes sepan también qué fue lo que nos ayudó a sobrevivir y sobreponernos a estas atrocidades. [...]

No tengo grandes cosas que darles ni grandes verdades que enseñarles, mi único «tesoro» es éste: darles una partecita de lo que viví y sentí y lo que pude aprender de eso... Pero hoy, cuando miro atrás y veo cuanto amor continuó rodeándonos, reafirmo más que nunca que nada ha sido en vano. Ustedes tres, mis hijos queridos, son prueba de ello. Ojalá en éstas páginas incompletas, con recuerdos fragmentados, puedan entender y encontrarme un poquito más. (Carta de Gianella Peroni en Memoria para Armar, vol. 2, 2002: 31-39)

42 En la carta, Gianella revela a sus hijos los sufrimientos y vejaciones pasadas, como parte de un proceso de sanación y reconciliación con su pasado y su relato genuino, pero también se centra en un relato de amor, solidaridad y momentos compartidos de risas y lágrimas con sus compañeras de periplo: momentos de familiaridad que la «arroparon» como una capa protectora en los momentos más oscuros y la ayudaron a sobrevivir. 
43 un testimonio a la vez más explícito - por ser enunciado en primera persona por primera vez (anteriormente los relatos eran más bien colectivos y en plural) y en tono más personal (individual) y emocional que en una conversación casual entre padres e hijos. La madre que enuncia y escribe sabe que dice algo trascendente, que sus hijos van a tomar un tiempo para digerir. Son cartas escritas para que los hijos ya jóvenes adultos las procesen a su tiempo. Los hijos en ese momento tienen edad similar a la que los padres militantes tenían al momento de la represión. Varias cartas, incluida la de Gianella, fueron leídas en público en Montevideo en junio de 2001 por artistas profesionales en el contexto de un espectáculo teatral al servicio del proyecto colectivo de verdad Memoria para Armar, uno de los primeros en este proceso, causando gran conmoción. Los testimonios fueron luego publicados en 2002-2003 en varios volúmenes, para pasar al acervo cultural de la era ${ }^{12}$.

\section{Avances del Grupo de Trabajo Verdad y Justicia (2015-2016)}

recientemente, el Grupo de Trabajo Verdad y Justicia fue establecido en mayo de 2015 para impulsar las políticas de esclarecimiento de la verdad sobre los delitos de lesa humanidad perpetrados por el Estado durante la dictadura y el período de violencia previa a ella, a los efectos de que el Estado asuma su responsabilidad y el pleno ejercicio de la justicia en estos casos. Fue instituido en febrero de 2015 al comenzar el tercer gobierno del Frente Amplio y el segundo mandato del Presidente Vázquez, que, desde 2005, es uno de los pioneros de los avances más significativos en este campo. En marzo de 2016, dicha institución acaba de anunciar su plan de trabajo ${ }^{13}$.

Las investigaciones oficiales sobre el tema existentes en Uruguay son relativamente recientes: activadas primero desde el 2003 con la Comisión para la $\mathrm{Paz}^{14}$, lo fueron en especial desde 2005 en el contexto del esclarecimiento de las desapariciones forzadas por el Presidente Vázquez, quien ya en su primer mandato (2005-2010) ordenó investigar oficialmente el destino de los desaparecidos, a través de un convenio con la Universidad de la República, que produjo un importante informe oficial, la Investigación Histórica sobre Detenidos Desaparecidos ${ }^{15}$, tan postergado desde $1986^{16}$.

A 40 años de los hechos, desde la sociedad civil continúa la demanda de importantes sectores de la población de no cerrar el tema y continuar en los avances para desobstaculizar el acceso de las víctimas y la sociedad civil a la verdad y responder a la demanda histórica de justicia. Como dijeran miembros del grupo, «soplan vientos de cambio» ${ }^{17}$. Este nuevo grupo es muestra de los avances, aunque lentísimos y a pesar de los obstáculos, de un proceso irrenunciable de los uruguayos y uruguayas todos ${ }^{18}$ no solamente de construcción de la memoria sino también de esclarecimiento de los hechos, reivindicación del derecho a la justicia y proceso legal, al resarcimiento legal y social y del derecho a la no-repetición, como lo expresara asimismo el reciente infome del relator especial de la ONU Pablo de Greiff. En palabras de su comisionado, ex-diputado y celebrado activista en derechos humanos, abogado de derecho internacional Felipe Michelini, este proceso de avances y retrocesos es resultado de un largo proceso de sedimentación del trabajo de décadas por las familias y los movimentos sociales, en particular las campañas populares contra la Ley de Caducidad (en 1987-1988 y 
nuevamente en 2009) y desde la primera organización de la Marcha del Silencio saliendo del período de latencia (1996) hasta este próximo 20 de mayo del corriente (2016), aún reivindicando la lucha contra la impunidad y el derecho al acceso a la justicia y la verdad (Michelini, 2011). Las expectativas están abiertas y la lucha por justicia y contra la impunidad tanto en el seno de la sociedad civil como dentro de los poderes del Estado continúa. Si las fuerzas inspiradas en el totalitarismo siempre han requerido que la memoria de la Historia y sus ciudadanos «den vuelta la página», el proceso uruguayo muestra con contundencia que «hay que poder leer la página antes de darla vuelta» ${ }^{19}$.

\section{Conclusiones}

Este caso demuestra cómo las memorias colectivas en la post-transición no son solamente determinadas por los intereses de poderosas élites (top-down), sino que también son resultado de poderosos mecanismos sociales y culturales de renovación socio-política y cultural en la sociedad civil, a pesar de los aparentes obstáculos políticos «totales» del oblivion. Estos mecanismos incluyen:

1. Procesos generacionales familiares, culturales y políticos de renovación, en tanto los testigos directos y los sujetos que experienciaron los eventos puedan relatar aspectos de los sentidos de sus experiencias a las generaciones más jóvenes, dentro de las familias, comunidades sociales y políticas, a través de símbolos narrativos, lecciones morales y otras formas ejemplares que nutren las emociones, lenguaje y juicios colectivos contemporáneos;

2. La presencia de testigos vivientes que ganan notoriedad pública y se transforman en transmisores públicos de versiones alternativas de la memoria. Ello incluye los procesos legales judiciales nacionales e internacionales que implican un relato legitimador;

3. Otros obstáculos a la «re-invención» irrestricta o borramiento del pasado por las élites, a través precisamente de la existencia arraigada de corrientes subterraneas de la memoria sustentada en "comunidades de memoria», grupos sociales activos que generan versiones alternativas y procesos culturales contestatarios que confrontan y coexisten con otras versiones oficiales y no oficiales de la Historia y son evidencia de este proceso contencioso del periodo en cuestión. Ejemplo de eso serían comunidades profesionales como antropólogos forenses investigando restos ilegales y hallazgos óseos, hallazgos de archivos ocultos o nueva documentación pública que provee plataformas para el debate histórico, o publicación de cartas, diarios, relatos de testigos directos o testimonios, obras narrativas de ficción sobre el periodo, etcétera. A pesar de intentos por expurgar u ocultar archivos, documentos y cuerpos, el borramiento del pasado rara vez puede ser completo.

Las tres décadas de transición uruguaya son ejemplo ilustrativo de cómo ésta ha sido un proceso altamente contestado y paradójico, con muchos cabos sueltos y puntos ciegos, a pesar de su sistematicidad y persistencia. Por último, las políticas del oblivion no pudieron satisfacer las expectativas populares de paz y reconciliación social a través de la justicia y las responsabilidades del Estado, y por última fallaron en su objetivo explícito de eliminar la polarización y sellar las cuestiones pendientes del pasado. Lo que muestra la evidencia de investigaciones en lo político, cultural e histórico de las transiciones tipo oblivion -más extendidas a nivel mundial de lo que se admitía hasta recientemente en medios académicos- es que aún cuando las políticas de transición tuvieron un éxito político relativo a corto plazo, no lograron objetivos más amplios para la sociedad a largo plazo, contribuyendo con fuerza, por el contrario, a amplificar el problema de los derechos humanos en el futuro. Pasada una breve década, las memorias del terrorismo de Estado de los ciudadanos y las luchas por el derecho a la justicia y la verdad, por último no 
desaparecieron ni fueron borrados. Por el contrario, retornaron desde la esfera sociocultural e intersubjetiva a la arena política para desafiarla, en un movimiento que ha crecido consistentemente y a través de ya tres generaciones.

Eso demuestra elocuentemente que el pasado no es un pasado permanentemente pasado, sino que permanece, latente, y se hace cada vez más presente. En años recientes ha habido gestos y eventos significativos de renovado reconocimiento público, tanto a nivel nacional como regional, de los reclamos por la verdad y la investigación acerca del destino final de los desaparecidos y la emergencia de otros grupos de problemas pendientes. Han sido reclamos persistentes por parte de aquellas personas y grupos que tuvieron familiares ejecutados y asesinados, que sufrieron prisión prolongada, torturas, abusos y violencias sexuales - particularmente en los últimos años vale destacar el reconocimiento específico de estos crímenes perpetrados contra mujeres y menores durante la tortura y hasta incluso el tema de los exiliados comienza también a emerger, además de innovadoras investigaciones y representaciones en la esfera cultural, sobre lo que significara la vida diaria bajo la represión estatal. Estos reclamos finalmente pudieron reaparecer en la arena pública y desde la sociedad civil, empujar la agenda política para efectuar transformaciones políticas y culturales. Este legado continúa ocupando espacio tanto público como privado en los afectos y la imaginación, dentro de las relaciones sociales y el área cultural y política (lo que llamo el nivel intersubjetivo) en donde se forman y toman las decisiones sociales y políticas. Las políticas del oblivion y la impunidad también trajeron una concomitante persistencia de una cultura de la impunidad -cuyas raíces profundas datan de antes de la crisis de la democracia en los 60- donde estos discursos dominantes permearon y se expandieron fuertemente a nivel de sectores de la sociedad civil, particularmente entre aquellos que no se han sentido identificados con las víctimas ni afectados por la violencia del Estado. Ya es tiempo de que se vaya ampliando el círculo de reconocimiento de estos procesos, tanto a nivel social como académico, y que se reconozca cómo impunidad, oblivion y memoria están íntimamente conectados.

A más de cuatro décadas de la escalada de violencia del terrorismo de Estado, aún no tenemos una noción acabada de su profundidad, del grado de sus silenciamientos y zonas oscuras, ni de la intensidad y magnitud de los daños provocados tanto por la violencia de Estado como también por su longeva y resiliente impunidad. El caso uruguayo demuestra no solo que la memoria es más resiliente que el olvido sino también que las acciones contra la impunidad valen la pena, en el sentido cultural histórico, generacional y político, contra los crímenes de lesa humanidad. Esa tarea seguirá en pie, sin duda, en las nuevas generaciones.

\section{BIBLIOGRAFÍA}

ALEXANDER Jeffrey A. \& SMELSER Neil (2004), Cultural Trauma and Collective Identity, Berkeley: University of California Press.

AMNISTÍA INTERNACIONAL (1979), Uruguay: Death under Torture 1975-1977, London: Amnesty International Publications. 
AMNISTÍA INTERNACIONAL (1983), Report on Human Rights Violations in Uruguay, London: Amnesty International Publications.

BERGERO Adriana \& REATI Fernando (eds.) (1997), Memoria colectiva y políticas de olvido: Argentina y Uruguay, 1970-1990, Rosario: Beatriz Viterbo.

BERGMAN Martin S. \& Jucovy Milton E. (1982), Generations of the Holocaust, New York: Basic Books. BLIXEN Samuel (1995), El vientre del Cóndor: del archivo del terror al Caso Berríos, Montevideo: Brecha. BURT Jo-Marie, FrIED AmILIVIA Gabriela \& LeSSA Francesca (2013), «Civil Society and the Resurgent Struggle against Impunity in Uruguay», International Journal of Transitional Justice, 7, 306-327.

CARUTH Cathy (ed.) (1995), Trauma: Explorations in Memory, Baltimore: John Hopkins University Press.

COMISIÓN PARA LA PAZ (2003), Informe Final (10 de abril de 2003), Presidencia, Montevideo: IMPO.

DANIELI Yael (ed.) (1998), International Handbook on Transgenerational Legacies of Trauma, Oxford: Oxford University Press.

DinGES John (2004), The Cóndor Years: How Pinochet and His Allies Brought Terrorism to Three Continents, New York: New Press.

ERIKSON Kai (1995), «Notes on Trauma and Community», C. Caruth (ed.), Trauma: Explorations in Memory, Baltimore: John Hopkins University Press.

FABBRI Edda (2007), Oblivion, Montevideo: Del Caballo Perdido.

FEITLOWITZ Marguerithe (1998), Lexicon of Terror: Argentina and the Legacies of Torture, Oxford: Oxford University Press.

FRIED AMILIVIA Gabriela (1993), Les stratégies de l'identité culturelle chez les jeunes Uruguayens après l'autoritarisme d'État (MA thesis), Université Paris-Diderot (Paris 7) Jussieu.

FRIED Amilivia Gabriela (2001), «Memorias que insisten: la intersubjetividad de la memoria y los hijos de detenidos desaparecidos por la dictadura militar argentina, 1976-1983», B. Groppo, P. Flier \& C. Feld (eds.), La imposibilidad del olvido: recorridos de la memoria en Argentina, Chile y Uruguay, La Plata: Al Margen, 127-150.

FRIED AMILIVIA Gabriela (2004), The Transmission of Traumatic Memories across Generations in Uruguay: The Experiences of Families of the Disappeared, Political Prisoners, and Exiles after the Era of State Repression, 1973-1984 (PhD diss.), University of California, Los Angeles.

FRIED AMILIVIA Gabriela (2006), «Piecing Memories Together after State Terror and Policies of Oblivion in Uruguay: The Female Political Prisoners' Testimonial Project, 1997-2004», Social Identities, 12(5), 543-562.

FRIED AMILIVIA Gabriela (2009), «Remembering Trauma in Society: Forced Disappearance and Familial Transmissions after Uruguay's Era of State Terror, 1973-2001», N. Packard (ed.), Sociology of Memory: Papers from the Spectrum, Cambridge: Cambridge Scholars Press, 135-158.

FRIED AMILIVIA Gabriela (2011), «Private Transmission of Traumatic Memories of the Disappeared in the Context of Transitional Politics of Oblivion in Uruguay (1973-2001): 'Pedagogies of Horror' Among Uruguayan Families», F. Lessa \& V. Druliolli, Memory of State Terrorism in the Southern Cone: Argentina, Chile, and Uruguay, New York: Palgrave Macmillan, 157-178. 
FRIED AMILIVIA Gabriela (2012), «Living to Tell the Story: Healing, Social Denial and Redress in Uruguay», B. Charbonneau \& G. Parent (eds.), Peace Building, Memory, and Reconciliation: Bridging Top-Down and Bottom-Up Approaches, London: Routledge, 72-90.

FRIED AMILIVIA Gabriela (2016a), «Sealing» and «Un-sealing» Uruguay’s Transitional Politics of Oblivion: Waves of Memory and the Winding Road to Memory and Justice (1985-2015)», R. Villalón (ed.), «The Politics of Memory Making in Latin America», Latin American Perspectives, 3.

FRIED AMILIVIA Gabriela (2016b), State Terrorism and the Politics of Memory in Latin America: Generations of Post-Dictatorship Uruguay (1984-2004), New York: Cambria.

FRIED Amilivia Gabriela (2016c), «Caducidad, Oblivion, y la memoria social del terrorismo de estado en el Uruguay de transición: las "brechas" a la impunidad», P. Galain-Palermo (ed.), ¿Justicia de transición? Mecanismos políticos y jurídicos para la elaboración del pasado, Valencia: Tirant lo Blanch, 123-142.

FRIED AMILIVIA Gabriela \& LESSA Francesca (eds.) (2011), Luchas contra la impunidad: Uruguay, 1985-2011, Montevideo: Trilce. En particular «Las múltiples máscaras de la impunidad en el Uruguay: la Ley de Caducidad, desde el Sí Rosado hasta los desarrollos recientes», 31-46.

FRIED AMILIVIA Gabriela, LeSSA Francesca \& Michelini Felipe (2016), «El Cóndor en la Bruma: Capítulo del Cóndor en Uruguay (1975-1994)», Instituto de Políticas Públicas de Derechos Humanos del Mercosur (IPPDH-Mercosur) (eds.), El Plan Cóndor: 40 Años, Buenos Aires/Mercosur: IPPDH.

FRIED AMILIVIA Gabriela \& TAKITA-ISHII Sachiko (2014), «The Intersubjectivity of Memory», Paper presented to the International Sociological Association, Yokohama, Japan (17-20 July 2014).

FRIEDLAENDER Saul (1979), When Memory Comes, New York: Farrar, Strauss \& Giroux.

GALAIN-PALERMo Pablo (ed.) (2015), ¿Justicia de transición? Mecanismos políticos y jurídicos para la elaboración del pasado, Valencia: Tirant lo Blanch.

GATTI Gabriel (2014), Surviving Forced Disappearance in Argentina and Uruguay: Identity and Meaning, New York: Palgrave Macmillan.

GREIFF Pablo DE (2014), Informe Final sobre Uruguay, Documento de la ONU A/HRC/27/56/Add.2, New York: Asamblea General de la ONU (29 agosto).

HALBWACHS Maurice (1925), Les cadres sociaux de la mémoire, Paris: Presses universitaires de France. HALBWACHS Maurice (1992), On Collective Memory, translated by Lewis A. Coser, Chicago: University of Chicago Press.

HERZOG James (1982), «World beyond Metaphor: Thoughts on the Transmission of Trauma», M. Bergman \& M. Jucovy, Generations of the Holocaust, New York: Basic Books, 103-119.

LANDAU Saul (1988), The Dangerous Doctrine: National Security and U.S. Foreign Policy, Boulder: Westview Press.

LESSA Francesca (2013), Memory and Transitional Justice in Argentina and Uruguay: Against Impunity, New York: Palgrave Macmillan.

LESSA Francesca (2014), ¿Justicia o impunidad? Cuentas pendientes en el Uruguay de post-dictadura, Montevideo: Penguin Random House.

LESSA Francesca \& DRULIOLLE Vincent (2011), The Memory of State Terrorism in the Southern Cone: Argentina, Chile, and Uruguay, New York: Palgrave Macmillan. 
LESSA Francesca \& PAYNE Leigh A. (2012), Amnesty in the Age of Accountability: Comparative and International Perspectives, Cambridge: Cambridge University Press.

LEVEY Cara (2014), «Of HIJOS and Niños: Revisiting Postmemory in Post-dictatorship Uruguay», History and Memory, 26(2), 5-39.

LIRA Elizabeth \& CASTILLO Maria Isabel (1991), Psicología de la amenaza política y el miedo, Santiago, Chile: ILAS.

LIRA Elizabeth, SALIMOVICH Sofia \& WeInSTEIN Eugenia (1992), «Victims of Fear: The Social Psychology of Repression», J. E. Corradi, P. W. Fagen \& M. A. Garretón (eds.), Fear at the Edge: State Terror and Resistance in Latin America, Berkeley: University of California Press, 72-89.

Liscano Carlos (2007), «Preface», E. Fabbri, Oblivion, Cuba: Caballo Perdido, 1-4.

Madres y Familiares de URuguayos Detenidos Desaparecidos (ed.) (2004), a todos ellos. Informe de Madres y Familiares de Uruguayos Detenidos Desaparecidos, Montevideo.

MAuss Marcel (1967), The Gift: Forms and Functions of Exchange in Archaic Societies, New York: Norton.

MARCHESI Aldo (ed.) (2013), Ley de Caducidad, un tema inconcluso: momentos, actores, argumentos, 1986-2013, Montevideo: Trilce.

MARCHESI Aldo (2014), «Uruguay: los tiempos de la memoria», P. Winn, S. J. Stern, F. Lorenz \& A. Marchesi, No hay mañana si ayer, Montevideo: Banda Oriental, 121-204.

Michelini Felipe (2001), «La experiencia del Cono Sur en materia de comisiones de la verdad», J. Méndez, M. Abregu \& J. Mariezcurrena (eds.), Verdad y justicia. Homenaje a Emilio F. Mignone, Buenos Aires: IIDE, 173-206.

MiCHELINI Felipe (2011), «Contra la cultura de la Impunidad. Reflexión, compormiso y aprendizaje ante los nuevos desafíos», G. Fried Amilivia and F. Lessa (eds.), Luchas contra la impunidad: Uruguay, 1985-2011, Montevideo: Trilce, 47-60.

PIRALIÁN Helen (2000), Genocidio y Transmisión [1994], Buenos Aires: FCE.

PrAGER Jeffrey (1998), Presenting the Past: Psychoanalysis and the Sociology of Misremembering, Cambridge, Massachussets: Harvard University Press.

PRAGER Jeffrey (2003), «Lost Childhood, Lost Generations: The Intergenerational Transmission of Trauma», Journal of Human Rights, 2, 173-181.

PRAGER Jeffrey (2004), «Jump-Starting Timeliness: Trauma, Temporality, and the Redressive Community", Paper presented to the International Society for the Study of Time, Time and Memory Conference, Clare College, Cambridge, 26-29.

PRAGER Jeffrey (2006a), «Beneath the Surface of the Self: Psychoanalysis and the Unseen Known», American Journal of Sociology, 112, 276-290.

PRAGER Jeffrey (2006b), «Jump-Starting Timeliness: Trauma, Temporality, and the Redressive Community», J. Parker, M. Crawford \& P. Harris (eds.), Time and Memory, International Society for the Study of Time Conference, Amsterdam: Brill, 229-245.

PRAGER Jeffrey (2008), «Healing from History: Psychoanalytic Considerations on Traumatic Pasts and Social Repair», European Journal of Social Theory, 11, 405-420.

PRAGER Jeffrey (2009), «Melancholic Identity: Post-Traumatic Loss, Memory and Identity Formation», A. Elliot and P. du Gay, Identity in Question, Thousand Oaks, CA: Sage, 139-157. 
PRAGER Jeffrey (2011), «Danger and Deformation: A Social Theory of Trauma», American Imago, 68 (3), 425-448.

PRAGER Jeffrey (2015), «Danger and Deformation: A Social Theory of Trauma II. Disrupting the Intergenerational Transmission of Trauma, Recovering Humanity and Repairing Generations», American Imago, 72(2), 133-155.

Rico Álvaro (coord.) (2007), Investigación histórica sobre detenidos-desaparecidos, 5 tomos, Montevideo: Presidencia de la República, IMPO.

Rico Álvaro (coord.) (2009), Investigación histórica sobre la dictadura y el terrorismo de estado en el Uruguay, 1973-1985, Montevideo: Presidencia de la República-Universidad de la República, IMPO.

RICO Álvaro \& ACHÚGAR Hugo (eds.) (1995), Uruguay: cuentas pendientes. Dictadura, memorias y desmemorias, Montevideo: Trilce.

RICœUR Paul (1999), La memoria, la historia, el olvido, Buenos Aires: Siglo XXI.

RONIGER Luis \& SNAJDER Mario (1999), The Legacy of Human-Rights Violations in the Southern Cone: Argentina, Chile, and Uruguay, Oxford: Oxford University Press.

Schudson Michael (1989), «The Present in the Past versus the Past in the Present», Communication, 11, 105-113.

SERPAJ (Servicio Paz y Justicia - Uruguay) (ed.) (1989), Nunca más. Informe sobre la violación a los derechos humanos, 1972-1985, Montevideo.

SkAar Elin, Gianella Malca Camilla \& EIDE Trine (2015), After Violence: Transitional Justice, Peace, and Democracy, London: Routledge.

VILLALón Roberta (ed.), «The Politics of Memory in Latin America», Latin American Perspectives, 3.

VIÑAR Maren \& VIÑAR Marcelo (1989), Exil et torture, Paris: Denoël.

VIÑAR Maren \& VIÑAR Marcelo (1993), Las fracturas de la memoria. Crónicas para una memoria por venir, Montevideo: Trilce.

VolKAN Vamik D., Ast Gabriele \& GREER William F. Jr. (2002), The Third Reich in the Unconscious: Transgenerational Transmission and Its Consequences, New York: Brunner-Routledge.

WeINSTEIN Martin (1988), Uruguay: Democracy at the Crossroads, Boulder, CO: Westview.

WESCHLER Lawrence (1991), A Miracle, a Universe: Settling Accounts with Torturers, London: Penguin.

\section{NOTAS}

1. La desaparición se refiere a la detención y secuestro ilegales por agentes del Estado (frecuentemente personal militar o policial o agentes de inteligncia encubiertos) de personas sospechadas de actividades políticas de oposición. Para mayor descripción de este crimen, sus orígenes e implicaciones, ver el trabajo brillante de Feitlowitz(1998) y Gatti (2014). La desaparición ha sido catalogada como un crimen permanente y un crimen contra la humanidad. Ver Convención Internacional contra la Desaparición Forzada (1994) y Acuerdos de San José de Costa Rica, Corte Inter-Americana de Derechos Humanos (1992).

2. Ver Informes Amnistía Internacional de la época, especialmente 1979 y 1983; ver Weinstein (1988) y Weschler (1991).

3. Por ejemplo, ver Bergero \& Reatti (1997). 
4. Ley $n .^{\circ} 15.848$, denominda Ley de la Caducidad de la Pretensión Punitiva del Estado de diciembre de 1986. La Ley n. ${ }^{\circ} 18.831$ de octubre de 2011 restableció la pretensión punitiva para los casos comprendidos en dicha ley.

5. Para un desarrollo detallado de las «olas de memoria» de la transición uruguaya, ver Fried (2016a). Otros trabajos importantes al respecto incluyen Allier Montaño (2010), Lessa (2014) y Allier Montaño \& Crenzel (2015).

6. "A blow to the community's solidarity and sense of community that manifests belatedly over time» (Erikson, 1976 en Caruth, 1995: 185); traducción y énfasis propios.

7. Jeff Prager, teórico social de memoria y trauma (y psiconanalista) fue mi director de tesis doctoral en el departamento de Sociología de la Universidad de California Los Angeles (UCLA, 1999-2004).

8. Ver el trabajo de Ruth Leys (2000) para una historia de la emergencia de la noción de trauma.

9. Las traducciones de Prager son propias.

10. El énfasis es propio.

11. Énfasis propios.

12. Para más análisis de la creatividad e innovación de estos grupos de ex presas y exiliadas, ver Fried Amilivia (2006).

13. Documento preparatorio del Grupo de Trabajo por Verdad y Justicia, 13 de febrero de 2015; Plan de Trabajo presentado el 15 de marzo de 2016. Comunicación personal con Felipe Michelini, comisionado.

14. Ver informe final de la Comisión para la Paz: <www.usip.org/sites/default/files/file/ resources/collections/commissions/Uruguay-Report_Informal.pdf>.

15. La investigación fue confiada por primera vez a un extenso equipo profesional de historiadores, coordinados por Álvaro Rico, Gerardo Caetano, y el ahora fallecido ilustre historiador uruguayo José Pedro Barrán, para coordinar las investigaciones oficiales, centradas en desaparecidos (2007) y asesinados políticos (2008), así como un informe sobre la dictadura y el terrorismo de Estado en Uruguay (1973-1985). La publicación de cinco tomos es actualizada regularmente. El equipo de historiadores tuvo acceso a selecciones parciales disponibles de varios archivos estatales, entre ellos los de los Ministerios de Defensa, del Interior y de Relaciones Exteriores, no sin obstáculos por parte del mismo Estado y controversia. Los resultados se han publicado en un informe final en 2007-2009 y está disponible públicamente en internet en la página oficial de Presidencia: <http://archivo.presidencia.gub.uy/_web/ noticias/2007/06/2007060509.htm>.

16. El acceso público a archivos estatales y la historia de los múltiples ocultamientos de pruebas sería tema para un amplio capítulo aparte. A modo de resumen, es notable la reciente denuncia por la Fiscalía General de la Nacion del hallazgo en 2008 de un importante numero de cajas de archivos con «valiosa documentacion de la dictadura» y posiblemente del Plan Cóndor, sustraídas de los archivos oficiales del Ministerio de Defensa -en su momento denunciadas por la entonces ministra Azucena Berruti- y escondidas en casa de un familiar de un militar, Coronel Castiglioni, recientemente fallecido, cajas finalmente incautadas por el poder público (jueza penal Larrieu) dentro del la investigación del caso de Fernando Miranda. Ver «Archivos Incompletos», La Diaria Montevideo, 5 de octubre 2015, <http://ladiaria.com.uy/articulo/2015/10/archivo-incompleto/>. 17. Entrevista a miembro de la comisión verdad y justicia, 18 de febrero de 2015 . La comisión incluye representantes de amplios sectores civiles tradicionales y no tradicionales en derechos humanos y culturales, como los activistas de derechos humanos y políticos Felipe Michelini y Macarena Gelman, y acaba de anunciar su plan de trabajo al momento de cerrar la redacción.

18. Entrevista personal con Felipe Michelini, 20 Febrero 2015 en Los Angeles, California USA y comunicación personal, Los Angeles-Montevideo, 15 de marzo 2016.

19. Comunicación personal con Felipe Michelini, 20 Febrero 2015 en Los Angeles, California. 


\section{RESÚMENES}

Este trabajo pregunta cómo las memorias colectivas de experiencias de trauma social como el terrorismo de Estado en el Uruguay han perdurado para ser transmitidas a través de las generaciones, en el contexto de políticas transicionales de oblivion, políticas extremas de silenciamiento social y negación de los abusos a los derechos humanos sufridos a manos del Estado. Este trabajo ofrece puntos analíticos de reflexión hacia una concepción sociológica del trauma colectivo, en base al estudio del caso uruguayo, centrado en la experiencia de las víctimas del terrorismo de Estado bajo el régimen cívico-militar (1973-1984) y de las políticas transicionales post-autoritarismo (1985-2015).

Las reflexiones que aquí se resumen se basan en dos décadas de investigación etnográfica y sociocultural de las transmisiones de estas experiencias a nivel privado, familiar, comunitario y cultural. El texto concluye analizando las consecuencias y costos sociales y humanos de las políticas transicionales basadas en la llamada "pacificación», el olvido y el silenciamiento públicos hasta 2005, y posteriores avances en la última década. Las conclusiones subrayan la dinámica de las memorias emergentes en tanto conflictos subyacentes, previamente silenciados y no reconocidos en la esfera pública, desde la era de violencia política y del terrorismo de Estado a la era de la reemergencia de la memoria de este período a nivel colectivo y social.

This work asks how the collective memory of socially traumatic experiences after state terrorism in Uruguay have endured to be transmitted across generations, in the context of transitional policies of Oblivion, extreme policies aimed at social silencing and denial of the human rights abuses suffered in the hands of the state. This work offers some analytic points of reflection towards a sociological concept of collective trauma, based on the study of the Uruguayan case, focusing on the experience of victims of state terror under the civil-military regime (1973-1984) and the post-authoritarian transitional policies (1985-2015).

These reflections summarized here are based on two decades of ethnographic and socio-cultural research on the transmissions of these experiences in the private, familiar, community and cultural realms. The text concludes by analyzing the consequences and social and human costs of transitional policies of Oblivion based on what has been called reconciliation by "pacification", oblivion and public silencing until 2005, and the advances in the past decade. The conclusions underline the dynamics of emerging memories as the results of underlying conflicts, silenced and unrecognized in the public sphere, from the era of political violence and state terrorism to the era of the re-emergence of the memory at the social and collective levels.

Cet article s'interroge sur la façon dont les mémoires collectives d'expériences traumatiques collectives, comme le terrorisme d'État en Uruguay, ont perduré pour être transmises à travers les générations dans le contexte de politiques transitionnelles d'oblivion, politiques extrêmes de silenciation sociale et de négation des violations des droits de l'homme commises par des agents d'État. Il offre des points d'analyse et de réflexion pour une conception sociologique du traumatisme collectif en se basant sur l'étude du cas uruguayen et en se centrant sur l'expérience des victimes du terrorisme d'État sous le régime civil-militaire (1973-1984) et dans les politiques transitionnelles post-autoritaires (1985-2015). 
Les réflexions résumées ici sont basées sur vingt ans de recherches ethnographiques et socioculturelles des transmissions de ces expériences aux niveaux privé, familial, communautaire et culturel. L'article conclue en analysant les conséquences et les coûts sociaux et humains des politiques transitionnelles basées sur la dénommée « pacification », l'oubli et la mise sous silence, jusqu'en 2005 et les avancées de la dernière décennie. Les conclusions soulignent la dynamique des mémoires émergentes en tant que conflits sous-jacents, préalablement passés sous silence et non reconnus dans la sphère publique, depuis la période de la violence politique et du terrorisme d'État et jusqu'au moment de réémergence de la mémoire aux niveaux collectif et social.

\section{ÍNDICE}

Mots-clés: mémoire collective, traumatisme social, politiques d'oubli, politiques transitionnelles, impunité

Palabras claves: memoria colectiva, trauma social, políticas de Olvido, políticas transicionales, impunidad

Keywords: collective memory, social trauma, politics of Oblivion, transitional politics, impunity

\section{AUTOR}

\section{GABRIELA FRIED AMILIVIA}

California State University Los Angeles.

Profesora asociada de Sociología \& Programa de Estudios Latinoamericanos, California State University Los Angeles. Doctora en Sociología (UCLA, 2004) M.A. Sociología (UCLA, 1998); M.A. Sociología clínica (Université Paris 7, 1993); Licenciada en Psicología (Universidad de la República, Uruguay, 1989). 